\title{
Development and implications of technology in reform-based physics laboratories
}

\author{
Sufen Chen, ${ }^{1}$ Hao-Chang Lo, ${ }^{2}$ Jing-Wen Lin, ${ }^{3}$ Jyh-Chong Liang, ${ }^{4}$ Hsin-Yi Chang, ${ }_{7}^{5}$ Fu-Kwun Hwang, ${ }^{6}$ Guo-Li Chiou, ${ }^{7}$ \\ Ying-Tien Wu, ${ }^{8}$ Silvia Wen-Yu Lee, ${ }^{9}$ Hsin-Kai Wu, ${ }^{10}$ Chia-Yu Wang, ${ }^{7}$ and Chin-Chung Tsai ${ }^{1, *}$ \\ ${ }^{1}$ Graduate Institute of Digital Learning and Education, National Taiwan University of Science and Technology, Taipei 10607, Taiwan \\ ${ }^{2}$ Department of Digital Content \& Technology, National Taichung University of Education, Taichung 40306, Taiwan \\ ${ }^{3}$ Department of Curriculum Design and Human Potentials Development, National Dong Hwa University, Hualien 97401, Taiwan \\ ${ }^{4}$ Graduate Institute of Applied Science and Technology, National Taiwan University of Science and Technology, Taipei 10607, Taiwan \\ ${ }^{5}$ Graduate Institute of Science Education, National Kaohsiung Normal University, Kaohsiung 82446, Taiwan \\ ${ }^{6}$ Department of Physics, National Taiwan Normal University, Taipei 11677, Taiwan \\ ${ }^{7}$ Graduate Institute of Education, National Chiao Tung University, Hsinchu 30010, Taiwan \\ ${ }^{8}$ Graduate Institute of Network Learning Technology, National Central University, Taoyuan 32001, Taiwan \\ ${ }^{9}$ Graduate Institute of Science Education, National Changhua University of Education, Changhua 500, Taiwan \\ ${ }^{10}$ Graduate Institute of Science Education, National Taiwan Normal University, Taipei 11677, Taiwan
}

(Received 28 May 2012; published 16 October 2012)

Technology has been widely involved in science research. Researchers are now applying it to science education in an attempt to bring students' science activities closer to authentic science activities. The present study synthesizes the research to discuss the development of technology-enhanced laboratories and how technology may contribute to fulfilling the instructional objectives of laboratories in physics. To be more specific, this paper discusses the engagement of technology to innovate physics laboratories and the potential of technology to promote inquiry, instructor and peer interaction, and learning outcomes. We then construct a framework for teachers, scientists, and programmers to guide and evaluate technology-integrated laboratories. The framework includes inquiry learning and openness supported by technology, ways of conducting laboratories, and the diverse learning objectives on which a technology-integrated laboratory may be focused.

DOI: 10.1103/PhysRevSTPER.8.020113

PACS numbers: 01.40.Ha, 01.50.Pa, 01.50.Lc

\section{INTRODUCTION}

Advances in technology have stimulated new ways of teaching. Educational reformers have seen the use of technology as a solution to transform undergraduate science instruction [1]. Researchers have put tremendous effort and research resources into developing technology-enhanced instruction. Numerous reports have provided evidence regarding its effectiveness. Specifically, some studies have revealed that technology-enhanced inquiry instruction yields better learning results than typical instruction [2]. The present study synthesizes the research to discuss the development of reform-based laboratories and how technology may contribute to fulfilling the instructional objectives of laboratories in physics.

Laboratory or practical work is presumed to be crucial in science education. It can mentally and physically engage students in varying levels of inquiry, which is highlighted in reforms for K-12 [3,4] and undergraduate science education [1] but is, however, unattainable in traditional classroom settings [5]. Previous studies have revealed that most science teachers recognize its importance in science

\footnotetext{
*ctsai@mail.ntust.edu.tw
}

Published by the American Physical Society under the terms of the Creative Commons Attribution 3.0 License. Further distribution of this work must maintain attribution to the author(s) and the published article's title, journal citation, and DOI. education, as summarized by Dillon [6]. Nevertheless, not many consider it as a useful or effective teaching method. Students often fail to gain conceptual and procedural knowledge from laboratories [1,6]. A typical scenario involves cookbook-style experiments and students practicing low-level skills $[1,6]$. On the one hand, recipelike laboratory manuals have been criticized for distorting the teaching objectives of laboratories. On the other hand, teachers rely on such manuals because of their concerns regarding time and resource constraints in the classroom. Moreover, the Office for Standards in Education [7] in the United Kingdom reported that, in primary schools, scientific inquiry is variable and vulnerable, while in secondary schools, its range is narrow and focuses on a handful of experiments which are tested in the national examination. This report reveals the problem in many education systems, where national tests or other examinations in science regulate the number and quality of laboratories. Even in colleges, where no more national tests exist, laboratory experiments are designed to demonstrate certain phenomena, to allow students to collect data, and to practice to explain the data using concepts they have learned in textbooks, rather than to create active laboratory experiences for students [8] or the inquiry required for reform to occur [1].

Inquiry tasks in existing textbooks and undergraduate introductory courses capture few, if any, of the cognitive processes of authentic science $[8,9]$. Researcher-developed 
activities are relatively positive in that they highlight some features of authentic science, such as letting learners choose their own variables, build and revise theoretical models, and coordinate results from different types of studies [9]. Nevertheless, several essential features continue to be ignored. For example, handling of anomalous data and the social aspect of constructing scientific knowledge are still absent from tasks developed by researchers [9], as is error analysis in undergraduate science and engineering laboratories [10]. With the emergence of technology, can we bring laboratory experiments closer to authentic science or not? This paper discusses various roles that technology can play in improving inquiry learning. We illustrate examples of technology support for various levels of openness of inquiry.

Moreover, collaborative learning is a crucial element in laboratories. Researchers have developed several computerassisted cooperative approaches for teacher-student and student-student interactions in simulation-based and remote laboratories. We reflect on the use of the social network concept in Web-based laboratories. Furthermore, based on Bloom's taxonomy of learning objectives, we discuss multifarious aspects of educational objectives that could be achieved in technology-assisted laboratories and provide suggestions for curriculum designers and programmers to design authentic science activities. These discussions lead to a four-dimension framework for designing and evaluating technology-integrated inquiry tasks. Finally, this paper reviews the recent development of technology-integrated laboratories in physics, including microcomputer-based laboratories introduced in the late 1980s, the presently prevailing simulations and virtual laboratories, and the newly developed remote laboratories and augmented reality applications. We evaluate the advantages and disadvantages of these laboratories using the framework.

There have been frameworks for inquiry tasks [9], for practical work [11], and for Web-based interactive learning systems [12], to name a few. The framework constructed in this paper highlights the emerging use of technology in laboratory learning. Typically, designing a quality technology-integrated laboratory requires involving experts from different fields, including physics, science education, engineering, and computer science. A framework can serve as a guideline for the design and evaluation of such laboratories and can enhance effective communication among those involved.

\section{TYPOLOGY OF USING TECHNOLOGY IN LABORATORY LEARNING}

The following sections discuss how technology-enhanced laboratories promote active learning, scientific inquiry, cooperative learning, and competence in the cognitive, affective, and psychomotor domains. We have constructed a framework including these four dimensions as a result of the discussion.

\section{A. Roles of technology in laboratory learning}

Researchers can and have applied many possible technologies in laboratories. The key point of concern is whether the use of technology fosters students' understanding of science. Two broad functions technology can provide in laboratory learning are exploration and investigation. First, regarding the function of exploration, technology-enhanced laboratories offer students opportunities to explore phenomena or objects. They are efficiently supported by technology affordances such as multimedia, hyperlinks, and interactivity. Furthermore, Web-based technologies give students access to a vast amount of information. With thoughtful design, students link new information to existing knowledge by purposeful reading and evaluating the information via the Internet. Exploration of information and phenomena is expected to help students get acquainted with the usually demanding and often difficultto-imagine role and meaning of theory in physics.

Second, technology can support student investigation in laboratory work. Krajcik et al. [13] presented an investigation web to supplement science educators with examinations of the potential of inquiry in regular science classrooms. Their investigation web depicts five areas of inquiry including asking questions, designing investigations and planning procedures, collaborating and presenting findings, analyzing data and drawing conclusions, and constructing apparatus and carrying out investigations. The investigation web provides rubrics to examine whether technology-enhanced laboratories support students' inquiry.

Taking into consideration both the exploration of information and the investigation web, there are at least seven roles technology could play in laboratory learning:

(1) Messing about: exploring, getting familiar with phenomena or objects.

(2) Finding information: purposeful reading, evaluating the information.

(3) Asking and refining questions: making predictions or hypotheses.

(4) Planning and designing an investigation: designing experimental procedures, identifying variables to explore, defining variables operationally, controlling and manipulating variables.

(5) Carrying out the procedures: assembling the apparatus, using the equipment, following through on procedures, keeping track of ideas, making observations, collecting data.

(6) Making sense of data: analyzing, transforming and visualizing data, creating models, constructing scientific explanations, making conclusions.

(7) Sharing findings: communicating findings, talking to others, presenting ideas, receiving feedback.

Every laboratory may highlight only one or a few of these roles. For example, Finkelstein et al. [14] examined the effects of substituting a computer simulation for real laboratory equipment in a traditional large-scale 
introductory algebra-based physics course at a large research university. The Circuit Construction Kit (CCK) [15] was used to simulate the behavior of simple electric circuits. It provides an open work space where students can manipulate resistors, light bulbs, wires, and batteries. Moving electrons are explicitly shown to visualize current flow and current conservation. The results showed that the CCK helped students to develop an understanding of simple circuits and the skills associated with connecting the apparatus in various combinations and to collect data and make arguments about the circuits' behaviors. This means that technology enables students to explore and get familiar with phenomena and objects, carry out the procedures, and make sense of data.

Another simulation-based learning system for secondyear junior high school students provided background knowledge about optical lenses via hypertexts that allowed students to find or read purposefully and evaluate information related to the experiment topic [16]. The acquisition of the background knowledge by the participant was tested using an online evaluation, in which a minimum threshold of 80 points must be reached before conducting the experiment in order to ensure that the participants have acquired sufficient background knowledge. After exploring the background knowledge, the participants chose a problem, made predictions, and then started the experiment. The system displayed prompts to help the learners to perform the experiments. They could adjust their original hypothesis based on the concepts discovered in the experiment and use the mouse to click or drag components to observe relationships between and changes to each component. They could also check the learning-process records at any time, which kept track of their problems, hypotheses, the operational steps in the simulation exploration, conclusions drawn, and elapsed time. The technology plays roles such as finding information, making predictions or hypotheses, carrying out the procedures, and making sense of data in this system.

Using remote laboratories, Nickerson et al. [17] had mechanical engineering majors carry out vibration experiments. Before the remote experiments, the students familiarized themselves with the underlying physical principles, the experimental equipment, and the experimental procedure. They were also given the opportunity for a limited amount of direct hands-on interaction with the experimental setup. Then, they continued with more detailed experimental studies in a remote fashion. Typically, one week was given for the students to complete the additional experimentation and write the laboratory report. All technical issues related to the setup and calibration of the system as well as the subsequent data postprocessing could be handled in the on-site portion of the vibration laboratory. The technology (remote technique) plays a vital role in helping students make sense of the data.

Kelly and Crawford [18] used microcomputer-based laboratories (MBL) in a grade 12 advanced placement physics course. The equipment is composed of a force probe and a motion detector. The force probe and motion detector both send electronic signals to an interface box, and eventually a computer, which makes a graphical representation of the events. Students performed simple motion experiments such as walking in front of the motion detector to record their distance versus time and velocity versus time graphs, which characterize the role of carrying out the procedures, and the teacher asked them to analyze graphs from data acquired during oscillatory motion, which corresponds to the role of making sense of data. Finally, the teacher asked the students to explore a measurable phenomenon of their own choice, which corresponds to asking and refining questions.

Additionally, Zacharia and Anderson [19] developed a conceptual-based physics course, in which they asked postgraduate students to decide which variables to vary and which to keep constant before running a simulation, and to make the necessary observations. This design represents the role of planning and designing an investigation. Simply put, the use of technology supports students' experience of inquiry-based learning and the constructive process of science in the laboratory. These examples show that technology could play single or multiple roles in laboratories.

\section{B. Technology support for the openness of laboratory activities}

Degree of openness refers to the extent to which the instructor specifies tasks for students to perform in a laboratory. The National Research Council's first recommendation for undergraduate education reform in science, mathematics, engineering, and technology is that all students should be engaged in open-ended investigations [20]. Depending on the amount of information provided for students, researchers have identified four levels of openness for inquiry in science activities [21,22]. The lowest level is the traditional cookbooklike laboratory [21] or simple experiment [9], where students investigate a given question through a prescribed method and try to reproduce expected results. In other words, the teacher clearly specifies all tasks. Gallet [23] has stated that, "Recipe experiments tend to sterilize imagination and initiative, leave no room for hypotheses, trials, errors, individual responsibility in a group, and above all, preclude the students' involvement in the decision-making processwhich is so important to our modern society" (p. 73). Decision making is recognized as a crucial component of scientific literacy [24]. As the level of openness increases, the inquiry activities are less structured and learners are left to make more decisions. At the highest level—open inquirystudents formulate their own research questions, design the procedures, and draw their conclusions. They are conducting so-called "authentic" experiments.

Authentic experiments allow students to ask their own research questions, to design their methods to answer 
the questions by choosing appropriate equipment and procedures, and to construct a scientific account of the data [25]. Authentic experiments offer a context to experience inquiry and foster scientific and holistic reasoning, which is difficult to attain in regular instruction in class. Laboratories are unique settings for teaching and learning science. However, few school laboratory tasks are authentic experiments; instead, most are simple experiments [9].

Unlike authentic experiments, simple experiments are extremely simplified in terms of cognitive process, including question generating, research planning, variable controlling, data collecting, result explaining, theory developing, and science reading [9]. A simple experiment depicts a certain relationship between a single independent variable and a single dependent variable. Students are told what to measure and what to control. The relationship between observed variables is straightforward without complex data transforming or coordinating results from other studies. As a result, students might develop false conceptions regarding the purpose of research, coordination between theory and data, the theory-ladenness of methods, anomalous data, reasoning, and social construction of scientific knowledge [9].

However, even with all the support of theories and values, some research has found that students who conduct open-ended experiments do not perform as well as those who conduct prescriptive experiments in achievement tests and surveys of science process skills [26]. Why is there such an undesirable outcome? Some practical problems exist in implementing open inquiry. Gallet [23] admitted that the first tryout of open inquiry looked like "havoc in a bee-hive," although the students did develop scientific initiative, creativity, and autonomy in writing laboratory reports, and would not return to the cookbook laboratories. Arons [27] argued that neither cookbook experiments nor open inquiry are effective for conceptual development. The former are boring and upsetting for students and lose the impact of the learning. The latter are frustrating for students and lack firm justification of teaching objectives. From secondary science teachers' perspectives, the main difficulty of open inquiry is that students cannot work without set procedures [28]. Scaffolding or guidance is needed to fulfill the purpose of laboratory learning. Moreover, it is better if teachers customize the scaffolding to meet individual students' levels.

Are technology-integrated laboratories a new formula for students? We have observed that, typically, teachers are concerned that open-ended inquiry may be too demanding for students, and the pace of learning and instruction is hard to control. Moreover, many traditional instruments are hard to use and are unreliable. Students are discouraged when they fail to get the expected results by following the step-by-step procedure and cannot figure out what has gone wrong [25]. We argue that the use of technology in laboratories may relieve some of these concerns.
First of all, technology-enhanced laboratories make inquiry less demanding to students by the support of scaffolding and eliminating unrelated factors. The learning system can provide scaffolding such as prompts, guides, and menus for selection to develop students' inquiry ability and to enhance their success and satisfaction in doing an experiment. Teachers can adjust the scaffolding to meet students' needs, interest, and pace so as to make the learning process more student-centered. Moreover, simulationbased laboratories can lessen students' cognitive load by limiting unrelated factors. Students' attention is drawn to certain variables or phenomena.

Secondly, compared with traditional laboratories, technology-enhanced laboratories reduce the time spent data collecting and graphing $[18,29]$, so that students can try to modify their experiments in the same period of time. Time constraints have been one of the major reasons why teachers feel reluctant to introduce open inquiry. With the support of technology, some of the tedious work can be cut down, making time for more meaningful tasks such as generating research questions, improving experiments, interpreting data, designing new experiments, etc. Thus, students play a more active role, rather than simply being observers of science.

Thirdly, technology-enhanced laboratories increase accuracy. This gives students greater satisfaction. Specifically, many experiments related to heat and energy have huge errors when students carry them out in a traditional laboratory. Although students could practice error analysis and estimation from such experiments, they might have difficulties in observing the relationship between variables. Technology-enhanced laboratories such as MBLs and simulations create more reliable data so that students are able to draw meaningful conclusions. We believe that such satisfying and successful experiences are important for students to cultivate competence and positive attitudes toward inquiry.

Millar [11] has proposed the Practical Activity Analysis Inventory to assess the openness of a practical activity, measuring the involvement of students in different stages of inquiry, including (1) asking research questions, (2) using equipment, (3) designing procedures, (4) handling data, and (5) interpreting results. Rather than focusing on student involvement, however, this paper examines how technology is involved in each stage of inquiry to support the openness of practical activities. We have modified Millar's inventory by adding two tasks: variables to be manipulated (or what to measure) and a laboratory report. For many activities that are not completely open-ended, students may not be able to make decisions on the procedure or methods, but they are allowed to choose what to measure and what to report. A total of seven tasks help us to examine the degree of openness of a technologyintegrated laboratory. The following provides examples of using technology to deliver each task. 
For task 1, deciding on the question to be addressed, some technology-enhanced laboratory systems provide a question or hypothesis menu for learners to choose from [16]. Some use scaffolds to help learners generate their research questions, such as Deters' Student-Designed Labs Software [30]. We think that this task does not necessarily need to be arranged at the beginning of a laboratory. It could appear in the middle of a laboratory, where learners might move from inquiry of low openness to that of high openness. Moreover, it could be used for inspiring student thinking at the end of a laboratory.

Task 2, regarding the equipment to be used, is common in virtual laboratories where students can choose equipment or materials. For example, Jaakkola and Nurmi's [31] virtual laboratory for electric circuits allows students to move around the materials, including wires, light bulbs, resistors, battery voltage, and meters. Although the teacher specifies the questions and procedures for the students on the learning sheets in their study, the system actually allows learners to make their own circuits to test different ideas. Learners can decide on the procedures and variables under investigation, which fits into tasks 3 and 4. Finkelstein et al. [14] present a similar simulation and let students develop "methods to measure resistance in multiple ways" (p. 2) in the circuits. The Circuit Construction Kit [15] is another example for tasks 2-4.

Task 5 focuses on methods of handling data collected or data analyses. The openness on this task is crucial to instructional goals such as processing data, relating symbolic concepts to observed quantities, identifying relationships between variables, transforming data between different representations, and analyzing and reducing errors [32]. Simulations often produce graphs for students. Remote laboratories, such as in Nickerson et al. [17], generate authentic data for students to analyze, interpret, and draw conclusions from. In addition to simulations and remote laboratories, video clips were chosen by Brookes and Etkina [33]. Users can download and analyze the videos through QuickTime. Specifically for practice with handling data, videos, rather than Web-based simulations, are suggested because they can be enlarged and examined in greater detail. Data analysis can be done using Excel.

Technology can make it easier for students to interpret results in laboratories (task 6). As mentioned above, technology-assisted laboratories provide real-time graphs. Empirical studies have shown that this feature improves students' graph interpretation and modeling [34,35]. Specifically, Etkina and colleagues foster students' ability of explanation by asking them to make predictions based on experiments they observe online [33]. Students can repeat various experiments online in a short period of time to accumulate enough data. They practice interpreting data and predicting.

Finally, task 7 is concerned with writing laboratory reports. Open inquiry has no prescribed procedures or results. Students need to decide on what to report and how to present the results, such as using mathematics expressions or qualitative descriptions. Technology can enhance the quality of laboratory reports by integrating note-taking systems such as PrivNote and Evernote, templates [36], and teaching strategies such as the Science Writing Heuristic [37]. Researchers have also found that a peer review system, where students upload reports and review each other's reports, can improve students' writing in science [38]. Likewise, the Web 2.0 technique facilitates writing in a group. It is commonly used for sharing information. We can apply it to support collaborative writing of laboratory reports. In sum, technology can be used to promote students' involvement in each of the seven tasks. Technology offers different levels of support for students as well as openness of inquiry to learn the essence of doing laboratories.

\section{Ways of conducting technology-enhanced physics laboratories}

There could be three ways of conducting experiments: instructor or demonstrator demo, student individual work, and student group work. The use of a specific way is highly dependent on the materials and purposes of the laboratory. This section discusses how the involvement of technology changes the social dynamic of a traditional laboratory.

\section{Instructor or demonstrator demo}

Many physics teachers more or less demonstrate experiments. The demonstrator could be the instructor or a student who demonstrates the experiment under the supervision of the instructor. Typically, the demonstrator performs the procedures to familiarize the class with the experiments and guides them in reflecting on and interpreting the experimentation findings $[31,35]$. Furthermore, the demonstrators could afford students opportunities for discussion or reflection through immediate feedback to both the instructor's or students' questions and observations [39]. For example, Lemckert [39] developed novel teaching and learning tools which incorporated direct two-way interactions (combinations of computer-aided learning and the more conventional synchronous demonstrator-guided learning), showing their benefits such as enabling students to observe and participate in a real-time interactive experiment and permitting off-site students to interact with a reallife demonstrator.

\section{Student individual work}

Learning in a laboratory can take place as an individual or group activity. Some previous studies have explored the effects of technology used in physics experiments in an individual way [16,40]. Researchers have developed some computer-based simulations for learning physics to support individual students' acquisition and integration of 
scientific knowledge (e.g., [41]). These simulations allow students to test their hypotheses at their own learning pace. However, Manlove et al. [40] pointed out that students favored collaborative learning over individual learning. They found that, when students learned individually in the laboratory, they seldom applied crucial learning strategies, such as planning and self-monitoring.

\section{Student group work}

Most of the learning activities in laboratories take place in groups. The usage of technology may change the ways that students interact with peers or instructors [17]. The learning outcomes may change as a result. Hence, exploring and understanding how the technologies work and affect students' social learning patterns would be an important issue in realizing the impacts of technology integration.

Learning the conceptions of physics is sometimes very difficult. Instructors attempt to use strategies such as collaborative learning to overcome this problem. In physics learning, students frequently conduct experiments collaboratively, and most studies have used group learning strategies to facilitate students' learning in technologyenhanced laboratory learning environments [40,42]. For example, the thermal MBL of Russell et al. [35] nurtures peer interactions and discussions that allow students to naturally explore on their own. Therefore, the computer is interpreted as an essential member in the physics group learning and conversation dynamic. Furthermore, the study by Light and Glachan [43] showed that working in groups can be much more efficient, especially for work requiring complex problem solving processes. Through group learning, students can acquire more opportunities to understand the phenomena and to engage in conceptual change with peers who have diverse opinions and ideas. Recent studies have also indicated that undergraduate students in different locations could individually access the laboratory via the Internet; and remotely, they could process the laboratory as a group $[44,45]$.

\section{Educational objectives of technology-assisted laboratories}

A framework of classification for what we intend students to learn is important in science learning and teaching. So it is in technology-enhanced laboratory environments. One of the most widely used frameworks is the revised Bloom's Taxonomy [46], which includes three domains: cognitive, affective, and psychomotor. In this section, we take some examples and use this framework to introduce how technology helps students learn in a laboratory.

The cognitive domain refers to the subject matter involved and the levels of processing ideas or thinking. As originally defined by Bloom et al. [47] and revised by Anderson et al. [46], it consists of four categories of knowledge. Factual knowledge is the basic elements that students must be acquainted with in a discipline, such as terminology and specific facts in physics. Conceptual knowledge is concerned with "the interrelationships among the basic elements within a larger structure that enable them to function together" ([48], p. 214), such as physics theories and principles. Procedural knowledge focuses on the process of inquiry and skills and algorithms of designing appropriate procedures. A fourth, which is a new category in the revised taxonomy, metacognitive knowledge, involves knowledge about cognition and awareness of and self-knowledge about one's own cognition and thinking [48]. Hands-on adherents believe that students could attain these learning objectives by handling physical apparatus. Nevertheless, some educators show that the appropriate technology could also achieve equal effectiveness. For example, Nickerson et al. [17] presented an evaluative study comparing remote laboratories versus hands-on laboratories in a mechanical engineering course on machine dynamics and mechanisms. Their results suggest that undergraduate students learned conceptual knowledge and procedural knowledge equally well from both types of laboratories.

As for the affective domain, it describes the reasons why we react emotionally to a situation. Affective objectives typically target the perception and growth in attitudes, emotion, and feelings. It ranges from receiving or becoming aware of stimuli that evoke feelings to manifesting behavior characterized by a set of consistent and predictable values [49]. Technology-enhanced laboratories may foster students' development in the affective domain. Take the study by Nickerson et al. [17], for example. The study assessed what students valued about remote laboratories, and found that they valued the short amount of time it takes to run a remote laboratory, the convenience of being able to conduct the laboratory from where they are, and the schedule flexibility of being able to complete the laboratory at any time. Therefore, the students had high motivation and attained an understanding and appreciation of the practical advantages of remote laboratories [17].

The psychomotor domain is concerned with the ability to physically manipulate a piece of equipment or an instrument. Its objectives usually focus on change or development in behavior or skills, such as the speed, precision, procedure, or techniques applied in the execution of the task [50-52]. Development of these skills requires practice. It seems that the skills in this domain are cultivated exclusively in physical laboratories. However, recent research has challenged this concept. The results of recent studies suggest that psychomotor skills ought to be considered as experiences rather than as tactile senses. The study by Finkelstein et al. [14] is one of the few studies to show that properly designed simulations used in the right contexts can become more effective tools than real laboratory equipment. They developed a model of a suite of physics simulations for undergraduate students. 
TABLE I. Framework for technology-enhanced laboratories.

\begin{tabular}{ll}
\hline \hline Dimension & Category \\
\hline 1. Support to learning activities & a. Messing about \\
& b. Finding information \\
& c. Asking and refining questions \\
& d. Planning and designing an investigation \\
& e. Carrying out the procedures \\
& f. Making sense of data \\
& g. Sharing findings \\
2. Support to open inquiry & a. Asking questions \\
& b. Choosing equipment \\
& c. Designing procedures \\
& d. Deciding variables \\
& e. Analyzing data \\
f. Interpreting results & g. Reporting results \\
3. Ways of conducting & a. Demo \\
& b. Individual work \\
c. Educational objectives & c. Group work \\
& a. Cognitive (metacognitive, procedure, \\
& conceptual and factual knowledge) \\
& b. Affective \\
& c. Psychomotor \\
\hline
\end{tabular}

These simulations were accurate, highly visual, dynamic representations of physics principles. The results indicated that the students outperformed their counterparts in the coordination tasks of assembling a real circuit and describing how it worked. They thus attained psychomotor skills.

Waller and Foster [53] also claimed that a well-designed computer-based education Web program, whereby students learn to operate a virtual instrument outside of a laboratory before actually using it in the laboratory, significantly improved use of the real instrument, as users' hands-on learning time was significantly reduced. Their Web-based program was related to the use of gas chromatographs and mass spectrometers. With the assistance of this program, students could transfer their experience in the virtual laboratory to the physical laboratory, specifically regarding using software to calibrate and control an actual instrument. Thus, students gained the psychomotor skills in a shorter period of time compared with those who did not experience the Web-based program.

In summary, Table I displays the dimensions of the framework as well as their categories. This table can serve as a coding scheme to make a clear mapping of a technology-enhanced laboratory to a reform-based laboratory, including the activities, openness, conducting ways, and educational objectives supported by the design. It can also assist in improving communication between educators and programmers on the design of technology-based laboratories and examinations.

\section{POSSIBLE TECHNOLOGIES APPLIED IN LABORATORY DESIGN}

Researchers have used novel technologies to enhance students' learning in physics experiments, such as MBL $[18,29,54]$, simulation or virtual reality $[16,40,55]$, remote laboratories [17,39], and augmented reality (AR) [56-58]. The following introduces the features of each type of laboratory and their recent development. Their strengths and weaknesses are evaluated using the framework.

\section{A. MBL}

MBL refers to all laboratories that connect probes, analog-to-digital converters, and computers to measure, record, and analyze data. A MBL requires students to manipulate equipment as in traditional laboratories and, moreover, enables them to measure vast quantities of data over a very long or very short time interval. Previous studies have shown that MBLs save time spent on data recording and graphing [18,29]. Students therefore have more time to repeat an experiment or test different variables. They can also spare the time for interpretation of data and graphs $[34,35,59]$. Moreover, by employing MBLs, students with mild physical disabilities may perform experiments independently [60]. Thus the goal of science education for all may be achieved.

MBL tools can assist students when learning physics concepts and skills. MBLs considerably extend the range of investigations students can carry out in classrooms [29]. 
Furthermore, the new generation of MBL apparatus has the features of easy portability, temporary memory saving devices, geographic information systems (GIS) and Bluetooth, and is compatible with personal digital assistants (PDAs), smart phones, and tablets. These features greatly increase the number of topics about which students could inquire. MBL has evolved into the realm of mobile learning.

Regarding educational objectives, MBLs could cover all domains. Particularly, because of their feature of physical manipulation, learners could gain psychomotor skills. Theoretically, among these four types of laboratories, MBLs have the highest flexibility in many aspects. Their research questions, context, procedures, and data are less prescribed. Students could experience authentic inquiry. However, their flexibility is often limited by instructors. In other words, the effectiveness of MBLs relies heavily on instructors. Another drawback is the relatively high cost of the equipment, compared with traditional laboratories or simulations. Presumably, this makes MBLs less popular, and it is unlikely that there will be sufficient equipment for individual student work in a class.

\section{B. Simulation or virtual reality laboratories}

Simulation has become the most common type of technology-integrated laboratory. It requires minimal space, time, and budget [17]. The most popular or recommended Web sites are mostly based on simulations. Examples may be found at the Multimedia Educational Resource for Learning and Online Teaching (MERLOT) collection [61]. Compared with other types of laboratories, simulation-based laboratories are more manageable in terms of materials and accessibility. Users can carry out multiple trials in a short period of time. Most simulations or virtual reality laboratories are self-contained. Learners can independently conduct the experiments at their own pace. The effectiveness of simulations is not affected by instructors as much as it is with MBLs.

In simulation-based physics learning, students are engaged in inquiry activities rather than just witnessing the objects being presented [55]. They can set up several virtual situations and change the variables on their own. A virtual laboratory also makes students aware of the learning foci by means of prompts and by making accessible only a few variables which are directly related to the learning foci. Students are therefore not distracted by unnecessary factors. Nevertheless, the latter is a doubleedged sword. In most simulations, noise and distraction are completely controlled. Indeed, the majority of online laboratories are so clean that, when they work with cookbook manuals, they are play-safe recipes. Limitation of noise can enhance learning of science concepts [62], but oversimplified experiments would miss the particularity of laboratory learning and lose the impact of learning. In other words, unrelated factors and errors can be reduced, but need not be completely swept clean [62]. Designers have to seek a balance between conceptual learning and openness of investigation.

Recent development of computer simulations incorporates games to motivate students with challenges, user interactions, rapid feedback [63], and score competitions. We expect that this development would increase students' growth in the affective domain.

\section{Remote laboratories}

Internet technology has permitted students or learners who are located far away from a physical laboratory to conduct real-time physics experiments remotely [39]. For example, Nickerson et al. [17] built a remote laboratory for undergraduate students to learn mechanical vibration. The students started on site to set up, calibrate, and get acquainted with the equipment. Then, they operated the system from remote computers to conduct the rest of the experiment. They could study the questions of their choice, such as viscous damping, damping due to Coulomb friction, nonlinear effects, etc. They learned science concepts equally well in remote versus hands-on modes. Most students responded that remote laboratories are more effective than traditional laboratories. In addition, they can collect real data (unlike simulation) and conduct experiments rapidly over the Internet.

Moreover, through remote laboratory experiments, learners can initiate experiments and view the video process at any time instead of waiting for other learners to hand over all of the experimental equipment as in traditional laboratories [17]. In addition to this convenience, with the incorporation of synchronous and asynchronous communication, students can also interact with the demonstrator or peers while conducting the experiments through the remote laboratory technology [17,39]. However, a remote laboratory is often associated with specific apparatus which is not available in normal laboratories. As a result, the investigation is limited to a few experiments tied to the apparatus. It is not designed to support a high degree of openness.

\section{Augmented reality (AR)}

An AR environment consists of both virtual and real objects at the same time when conducting physics experiments, such as those in mechanics [57,58]. AR could be integrated with mobile learning and game-based learning. Scientists have been incorporating techniques such as sound and gesture recognition, geolocation, compass, quick response codes, cameras on handheld devices, mini projectors, mobile AR browsers, etc. Wii is an example of how real world action is being integrated with interactive digital media to create new learning experiences. Students can test their theories on speed [64] and can develop practical experiments in such a physical plus 
TABLE II. Features of different technologies in physics laboratories. ++, great potential; +, potential with some limitations; - , less friendly.

\begin{tabular}{|c|c|c|c|c|}
\hline & MBL & Simulation & Remote lab & AR \\
\hline Object & Real & Virtual & Real & Mixed \\
\hline Data & Authentic & Artificial & Authentic & Mixed \\
\hline Context & Physical & Virtual & Distant & Mixed \\
\hline Cost per use & High & Low & Low & Mixed \\
\hline \multicolumn{5}{|l|}{ Support to learning activities } \\
\hline Messing about & ++ & ++ & + & ++ \\
\hline Finding information & + & ++ & + & + \\
\hline Asking and refining questions & ++ & ++ & + & ++ \\
\hline Planning and designing & ++ & + & + & + \\
\hline Carrying out the procedures & ++ & ++ & ++ & ++ \\
\hline Making sense of data & ++ & ++ & ++ & ++ \\
\hline Sharing findings & ++ & ++ & ++ & ++ \\
\hline \multicolumn{5}{|l|}{ Support to open inquiry } \\
\hline Asking questions & ++ & + & - & ++ \\
\hline Choosing equipment & ++ & + & - & + \\
\hline Deciding procedures & ++ & + & - & + \\
\hline Deciding variables & ++ & ++ & - & + \\
\hline Analyzing data & ++ & ++ & ++ & ++ \\
\hline Interpreting results & ++ & ++ & ++ & ++ \\
\hline Reporting results & ++ & ++ & + & ++ \\
\hline \multicolumn{5}{|l|}{ Ways of conducting } \\
\hline Demo & ++ & ++ & ++ & ++ \\
\hline Individual work & + & ++ & ++ & ++ \\
\hline Group work & ++ & - & - & + \\
\hline \multicolumn{5}{|l|}{ Educational objectives } \\
\hline Cognitive & ++ & ++ & ++ & ++ \\
\hline Affective & ++ & ++ & + & ++ \\
\hline Psychomotor & ++ & - & - & + \\
\hline
\end{tabular}

virtual environment. Thus, active rather than passive learning is promoted. Like simulations, AR has great potential to motivate learners with games.

One of the main advantages of AR is that students can actually see three-dimensional objects. Therefore, they can understand some complex spatial problems or spatial relationships much better than through traditional presentations [57]. Sotiriou and Bogner [58] found that students' participation in physics AR activities positively influences their intrinsic motivations for learning physics. However, some problems exist in such advanced physics AR environments. For example, the difference between the virtual and real objects is obvious, making it hard for the objects to appear realistic and appealing when students are conducting the physics experiments [56]. Finally, some AR requires specific goggles, tablets, and equipment such as Wii. The extra cost may restrict its application to a few individuals.

Table II summarizes the unique features of the abovementioned laboratories. For MBL, learners manipulate real objects and authentic data in a physical context. In contrast, concepts or phenomena are often represented virtually in simulations and virtual laboratories. Remote laboratories are somewhat similar to MBLs, except for their distant context. They are often limited to experiments that utilize equipment not readily available in ordinary laboratories. $\mathrm{AR}$ is a mixture of virtual and real. Its application in education is emerging and seems to be fairly promising for the future.

These laboratory types, when carefully designed, could achieve our expectations of laboratory learning as emphasized in science education reforms. We have applied the framework to assess their potential (Table II). The results are tentative due to the continuing development of technology. They serve as an example of how to use the framework. Among the laboratory types, remote laboratories have limitations in many aspects of supporting inquiry learning, but they are the best choice for certain series of experiments that require unusual apparatus or are done in a distant space, for example, on Mars. For planning and designing experiments, MBL has a greater potential, because less has been predetermined by the designers. Moreover, MBL, simulation, and AR can offer training in asking and refining questions. However, regarding the questions learners can investigate, simulations and $\mathrm{AR}$ are not as open as MBL. Furthermore, MBL, simulation 
and AR may fulfill the affective objectives by the handson feature or the incorporation of games. Technologyenhanced laboratories may also stimulate positive emotions by giving successful experiences of experimentation. Finally, researchers and educators have started to combine any of these four types of laboratories to meet different educational objectives [45,57].

\section{CONCLUSION}

In this paper, we have discussed how technology may enhance students' inquiry in physics laboratories. Four kinds of technology-integrated laboratories, including MBL, simulation, remote laboratories, and AR, are illustrated. Technology-enhanced inquiry instruction provides opportunities for learners to explore and become familiar with phenomena or objects, to find essential information, and to make predictions or hypotheses. The advance of the Internet and mobile technology has considerably enhanced the flexibility of inquiry activities. Learners can plan or undertake a scientific investigation on a wide range of topics. By analyzing, transforming, and visualizing data, creating models, constructing scientific explanations, and making conclusions, learners make sense of data, construct concepts, and communicate with others.

Teachers can tailor technology-integrated laboratories for different levels of openness according to their teaching objectives and learners' inquiry ability. Learners may experience autonomy in some or all of the inquiry tasks, including deciding on research questions, designing procedures, measuring variables, analyzing data, interpreting data, and finishing or sharing reports. Science education reforms and the literature present a strong argument for open inquiry $[3,9,25]$. However, many reports have described its challenges in a typical educational setting [6]. Our discussion shows that the challenges in practice may be reduced by integrating technology.

Moreover, in a learning environment supported by technologies, learners can interact with peers, the instructors, or the interface in individual and/or group ways. Understanding how the technologies can be used in the laboratory might lead to the realization of novel experiences of interactions. For example, modern technologybased telecommunications could empower students to participate in synchronous or asynchronous interactive physics experiments, especially for off-site students [39]. Such an understanding might affect the design of the different forms of students' interactions for different types of learners and consequently increase their educational effectiveness [17]. For example, remote laboratories might be especially suitable for those students who possess a highly flexible learning style [17].

This paper is not intended to provide a comprehensive review of the literature. Rather, the focus is on the framework for designing and evaluating laboratory learning.
Section II starts by clarifying the inquiry learning supported by a technology-integrated laboratory, followed by student involvement in and technology support for various levels of openness. It should be noted that we are not promoting an all-features-included design. Some laboratories may highlight experimental methods, while others emphasize data analyses. Likewise, students who are not competent in doing inquiry would need more scaffolds and simplified tasks, whereas competent students may be able to conduct open inquiries. The last part of Sec. II helps designers to connect design features to diverse learning objectives. It can also be used to evaluate the educational value or impact of a technology-integrated laboratory. Overall, the framework we propose can be applied to examine the congruence between the use of a technology and what we intend students to learn. Physics educators are encouraged to use the proposed framework to carefully check the usage, the role, or the potential of technology when designing laboratories for physics learning.

This framework links technology-integrated laboratories to reform-based laboratories. Its implication is not bound to a specific type of technology. It also involves a wide spectrum of educational objectives, learning environments, and social interactions. These components are important in laboratory learning. Table I can be used as a checklist for designers to examine the strengths and limitations of their laboratories. Researchers can use a yes or no code for the categories and items. Furthermore, researchers can apply a Likert scale to classify the level of support or involvement of technology from none to very much.

This framework does, however, have several limitations. Firstly, we did not take into account how a teacher or student behaves in a laboratory. For example, students may play mindlessly. A teacher may turn an open-ended inquiry task into standard lab work by giving step-by-step instructions, or vice versa. According to Michael and Modell [8], instructors' intervention significantly influences students' learning in a laboratory. Our framework focuses on the design and evaluation of the design but not on how the design is actually used. We recommend that designers use the framework to outline the flexibility and objectives of their laboratories for users. Researchers may also use the framework as a coding category for classroom observations. Secondly, the main purpose of the framework is to help designers plan and reflect on the focus or comprehensiveness of their design. As a result, we have systematized the dimensions and categories but have not assigned each dimension and category different weights. In other words, we have not attempted to distinguish the importance among dimensions and categories. For example, in our framework, learning in the psychomotor domain is as important as in the cognitive domain. Researchers who are concerned with this issue may apply the Delphi method, for example, to estimate the weights. Finally, we have not included a discussion of interface 
design. Interfaces are important for human-machine interactions. Future studies may review the relevant models and techniques to provide designers with alternatives of interface design.

\section{ACKNOWLEDGMENTS}

This research project was supported by grants from the National Science Council, Taiwan (NSC No. 101-2631-S011-002 and No. 100-2631-S-011 -002).
[1] D. W. Sunal, E. L. Wright, and J.B. Day, Reform in Undergraduate Science Teaching for the 21st Century (Information Age Publishing, Greenwich, CT, 2004).

[2] H.-S. Lee, M. C. Linn, K. Varma, and O. L. Liu, How do technology-enhanced inquiry science units impact classroom learning?, J. Res. Sci. Teach. 47, 71 (2010).

[3] National Research Council, Inquiry and the National Science Education Standards (National Academic Press, Washington, DC, 2000).

[4] National Research Council, A Framework for $\mathrm{K}-12$ Science Education: Practices, Crosscutting Concepts, and Core Ideas (National Academic Press, Washington, DC, 2012).

[5] V. N. Lunetta, A. Hofstein, and M. P. Clough, in Handbook of Research on Science Education, edited by S. K. Abell and N. G. Lederman (Lawrence Erlbaum Assoc., Mahwah, NJ, 2007), pp. 393-431.

[6] J. Dillon, A Review of the Research on Practical Work in School Science (Kings College, London, 2008).

[7] Office for Standards in Education (Ofsted), Science in Secondary Schools (HMI/Ofsted, London, 2005).

[8] J.A. Michael and H.I. Modell, Active Learning in Secondary and College Science Classrooms: A Working Model for Helping the Learner to Learn (Lawrence Erlbaum Assoc., Mahwah, NJ, 2003).

[9] C.A. Chinn and B.A. Malhotra, Epistemologically authentic inquiry in schools: A theoretical framework for evaluating inquiry tasks, Sci. Educ. 86, 175 (2002).

[10] A.F. Mills and B.H. Chang, Error Analysis of Experiments: A Manual for Engineering Students (University of California, Los Angeles, CA, 2004).

[11] R. Millar, Analysing Practical Activities to Assess and Improve Effectiveness: The Practical Activity Analysis Inventory (PAAI) (University of York, York, England, 2009).

[12] C. Chou, Interactivity and interactive functions in webbased learning systems: A technical framework for designers, Br. J. Educ. Technol. 34, 265 (2003).

[13] J. S. Krajcik, P. C. Blumenfeld, R. W. Marx, K. M. Bass, J. Fredricks, and E. Soloway, Inquiry in project-based science classrooms: Initial attempts by middle school students, J. Learn. Sci. 7, 313 (1998).

[14] N. D. Finkelstein, W. K. Adams, C. J. Keller, P. B. Kohl, K. K. Perkins, N. S. Podolefsky, and S. Reid, When learning about the real world is better done virtually: A study of substituting computer simulations for laboratory equipment, Phys. Rev. ST Phys. Educ. Res. 1, 010103 (2005).

[15] Circuit Construction Kit, http://phet.colorado.edu/
[16] K. E. Chang, Y. L. Chen, H. Y. Lin, and Y. T. Sung, Effects of learning support in simulation-based physics learning, Comput. Educ. 51, 1486 (2008).

[17] J. V. Nickerson, J.E. Corter, S. K. Esche, and C. Chassapis, A model for evaluating the effectiveness of remote engineering laboratories and simulations in education, Comput. Educ. 49, 708 (2007).

[18] G. J. Kelly and T. Crawford, Students' interaction with computer representations: Analysis of discourse in laboratory groups, J. Res. Sci. Teach. 33, 693 (1996).

[19] Z. Zacharia and O.R. Anderson, The effects of an interactive computer-based simulation prior to performing a laboratory inquiry-based experiment on students' conceptual understanding of physics, Am. J. Phys. 71, 618 (2003).

[20] National Research Council, From Analysis to Action: Undergraduate Education in Science, Mathematics, Engineering, and Technology (National Academic Press, Washington, DC, 1996).

[21] R. L. Bell, L. Smetana, and I. Binns, Simplifying inquiry instruction: Assessing the inquiry level of classroom activities, Sci. Teach. 72, 30 (2005).

[22] M. D. Herron, The nature of scientific inquiry, Sch. Rev. 79, 171 (1971).

[23] C. Gallet, Problem solving teaching in the chemistry laboratory: Leaving the cooks ..., J. Chem. Educ. 75, 72 (1998).

[24] National Research Council, National Science Education Standards (National Academic Press, Washington, DC, 1996).

[25] R. Trumper, The physics laboratory-A historical overview and future perspectives, Sci. Educ. 12, 645 (2003).

[26] E. W. Osborne, Effects of level of openness in agriscience experiments on student achievement and science process skill development, J. South Agric. Educ. Res. 50, 75 (2000) [http://pubs.aged.tamu.edu/jsaer/vol50whole .pdf\#page $=75]$.

[27] A. Arons, Guiding insight and inquiry in the introductory physics laboratory, Phys. Teach. 31, 278 (1993).

[28] H. Staer, D. Goodrum, and M. Hackling, High school laboratory work in Western Australia: Openness to inquiry, Res. Sci. Educ. 28, 219 (1998).

[29] J. B. Brungardt and D. Zollman, Influence of interactive videodisc instruction using simultaneous-time analysis on kinematics graphing skills of high-school physics students, J. Res. Sci. Teach. 32, 855 (1995).

[30] K. M. Deters, Investigating a Computerized Scaffolding Software for Student Designed Science Investigations 
(University of Nebraska, Lincoln, NE, 2008); see also http://www.kellymorganscience.com/SDL/index.html.

[31] T. Jaakkola and S. Nurmi, Fostering elementary school students' understanding of simple electricity by combining simulation and laboratory activities, J. Comput. Assist. Learn. 24, 271 (2008).

[32] P. A. Kirschner and M. A. M. Meester, The laboratory in higher science education: Problems, premises and objectives, High. Educ. 17, 81 (1988).

[33] D. Brookes and E. Etkina, Physical phenomena in real time, Science 330, 605 (2010).

[34] D. D. Adams and J.W. Shrum, The effects of microcomputer-based laboratory exercises on the acquisition of line graph construction and interpretation skills by high school biology students, J. Res. Sci. Teach. 27, 777 (1990).

[35] D. W. Russell, K. B. Lucas, and C. J. McRobbie, Role of the microcomputer-based laboratory display in supporting the construction of new understandings in thermal physics, J. Res. Sci. Teach. 41, 165 (2004).

[36] A. A. Zucker and S. T. Hug, Teaching and learning physics in a 1:1 laptop school, J. Sci. Educ. Technol. 17, 586 (2008).

[37] K. A. Burke, T.J. Greenbowe, and B. M. Hand, Implementing the Science Writing Heuristic in the chemistry laboratory, J. Chem. Educ. 83, 1032 (2006).

[38] J.C. Liang and C.-C. Tsai, Learning through science writing via online peer assessment in a college biology course, Internet High. Educ. 13, 242 (2010).

[39] C. J. Lemckert, Incorporation of a demonstrator into internet-mediated laboratory experiments, Int. J. Eng. Educ. 19, 433 (2003) [http://www.ijee.ie/articles/Vol193/IJEE1359.pdf].

[40] S. Manlove, A. W. Lazonder, and T. de Jong, Collaborative versus individual use of regulative software scaffolds during scientific inquiry learning, Interact. Learn. Environ. 17, 105 (2009).

[41] http://phet.colorado.edu/

[42] Z.C. Zacharia, G. Olympiou, and M. Papaevripidou, Effects of experimenting with physical and virtual manipulatives on students' conceptual understanding in heat and temperature, J. Res. Sci. Teach. 45, 1021 (2008).

[43] P. Light and M. Glachan, Facilitation of individual problem solving through peer interaction, Educ. Psychol. 5, 217 (1985).

[44] E. Fabregas, G. Farias, S. Dormido-Canto, S. Dormido, and F. Esquembre, Developing a remote laboratory for engineering education, Comput. Educ. 57, 1686 (2011).

[45] C. A. Jara, F. A. Candelas, S. T. Puente, and F. Torres, Hands-on experiences of undergraduate students in automatics and robotics using a virtual and remote laboratory, Comput. Educ. 57, 2451 (2011).

[46] L. W. Anderson, D. R. Krathwohl, P. W. Airasian, K. A. Cruikshank, R.E. Mayer, P. R. Pintrich, J. Raths, and M. C. Wittrock, A Taxonomy for Learning, Teaching, and Assessing: A Revision of Bloom's Taxonomy of Educational Objectives (Longman, New York, 2001), Complete edition.

[47] B.S. Bloom, M. D. Engelhart, E. J. Furst, W. H. Hill, and D. R. Krathwohl, in Bloom's Taxonomy: A Forty-Year Retrospective, edited by L.W. Anderson and L. A. Sosniak (University of Chicago Press, Chicago, 1994).
[48] D. R. Krathwohl, A revision of Bloom's taxonomy: An overview, Theory Into Practice 41, 212 (2002).

[49] D. R. Krathwohl, B. S. Bloom, and B. B. Masia, Taxonomy of Educational Objectives, the Classification of Educational Goals. Handbook II: Affective Domain (David McKay, New York, 1973).

[50] R.H. Dave, in Developing and Writing Educational Objectives, edited by R.J. Armstrong (Educational Innovators Press, Tucson AZ, 1970), pp. 33,34.

[51] A. J. Harrow, A Taxonomy of the Psychomotor Domain: A Guide for Developing Behavioral Objectives (David McKay, New York, 1972).

[52] B. J. Simpson, The classification of educational objectives: Psychomotor domain, Illinois J. Home Econ. 10, 110 (1966).

[53] J. C. Waller and N. Foster, Training via the web: A virtual instrument, Comput. Educ. 35, 161 (2000).

[54] A. A. Zucker, R. Tinker, C. Staudt, A. Mansfield, and S. Metcalf, Learning science in grades 3-8 using probeware and computers: Findings from the TEEMSS II Project, J. Sci. Educ. Technol. 17, 42 (2008).

[55] T. Jaakkola, S. Nurmi, and K. Veermans, A comparison of students' conceptual understanding of electric circuits in simulation only and simulation-laboratory contexts, J. Res. Sci. Teach. 48, 71 (2011).

[56] C. Chae and K. Ko, Introduction of physics simulation in augmented reality, in Proceedings of the International Symposium on Ubiquitous Virtual Reality, Gwangju, South Korea, 2008 (IEEE, New York, 2008).

[57] H. Kaufmann and B. Meyer, Simulating educational physical experiments in augmented reality, in Proceedings of ACM SIGGRAPH ASIA 2008 Educators Program (ACM, New York, 2008), doi: 10.1145/ 1507713.1507717.

[58] S. Sotiriou and F. Bogner, Visualizing the invisible: Augmented reality as an innovative science education scheme, Adv. Sci. Lett. 1, 114 (2008).

[59] C. Berger, C. R. Lu, S. J. Belzer, and B.E. Voss, in Handbook of Research on Science Teaching and Learning, edited by D. L. Gabel (MacMillan, New York, 1994), pp. 466-490.

[60] K. Bernhard and J. Bernhard, Science for all-Using microcomputer based laboratory tools for students with physical disabilities, in Proceedings of the International Conference on Practical Work in Science Education, Copenhagen, 1998, http://www.itn.liu.se/ jonbe/fou/ didaktik/papers/Sci\%20for\%20all.pdf.

[61] http://physics.merlot.org/

[62] S. Chen, The view of scientific inquiry conveyed by simulation-based virtual laboratories, Comput. Educ. 55, 1123 (2010).

[63] National Research Council, Learning Science Through Computer Games and Simulations (National Academic Press, Washington, DC, 2011).

[64] L. E. Holmquist, W. Ju, M. Jonsson, J. Tholander, Z. Ahmet, S. I. Sumon, U. Acholonu, and T. Winograd, Wii science: Teaching the laws of nature with physically engaging video game technologies, in Proceedings of the ACM Computer Human Interaction Conference, Atlanta, GA, 2010 (ACM, New York, 2010). 